\title{
JSC "GLONASS" innovative navigation and information technologies in Uzbekistan
}

\author{
$G B$ Yusupkhodjaeva ${ }^{1}$ \\ ${ }^{1}$ Tashkent State Technical University named by Islam Karimov, Tashkent, Uzbekistan
}

\begin{abstract}
The article gives recommendations on the effective use of the State Automated Information System for Emergency Response in case of road accidents on the roads of the Republic of Uzbekistan, the introduction and development of the use of intelligent transport systems at transport enterprises of the Republic of Uzbekistan.
\end{abstract}

Keywords. transport, development, systematization, efficiency, services, competition, intelligent transport systems.

\section{Introduction}

The country is taking consistent measures to improve the road safety system, implementing reforms in the digital economy, creating conditions for introducing public-private partnership mechanisms aimed at improving the quality of life of the population, improving the investment climate and business environment. To further improve the road safety system and the introduction of modern information and communication technologies in the transport system of the Republic of Uzbekistan in the framework of the decree of the President of the Republic of Uzbekistan dated July 11, 2017, No. PP-3127 "On measures to further improve the road safety system."

In the Republic of e Uzbekistan on the creation of information systems, "the State Automated Information System emergency response in the road and other accidents on the roads of the Republic of Uzbekistan" (hereinafter GAIS ERA) and "Intellectual geo platforms the Republic of Uzbekistan " (hereinafter - IGP), as part of the current Law on Public-Private Partnership, on the determination by the Operator of GAIS ERA and IHP (hereinafter referred to as the Operator) - LLC " SMARTGEO ";

LLC "SMARTGEO" is the general partner of JSC "GLONASS" in the Republic of Uzbekistan. JSC "GLONASS" represents Russian high-tech navigation and information technologies - the emergency response system in case of accidents "ERA-GLONASS", monitoring of transport and cargo, high-precision positioning and other services in the field of transport security, communications, logistics, ecology, agriculture, etc.

Together with a local partner, SMARTGEO, GLONASS JSC presented a Russian-Uzbek project to create a similar system in the Republic of Uzbekistan.

The Smart Geo company promotes the Uzbek- Russian cooperation in the geoinformation segment and has been the official representative of GLONASS JSC (Russia) in
Uzbekistan for about two years.

In October 2019, the company signed a memorandum of cooperation for the development of navigation and information technologies in the transport sector with GLONASS JSC.

Within the framework of this cooperation, an analog of the Russian Emergency Response Program to accidents "ERA-GLONASS" for Uzbekistan is being developed. analogs of this effective system are successfully operating in Kazakhstan, European countries, Japan and the USA.

\section{Studying the effect}

The plans include the implementation of joint projects with Russian partners to provide specialized services to exporting companies for the installation of so-called "smart seals" on freight vehicles delivering export products from Uzbekistan to Russia or through Russia. Thanks to such seals, the exporter, being in his office, will be able to constantly monitor the movement of goods, temperature conditions, and other indicators. It will also help to increase the transit potential of Uzbekistan.

Following the Concept of ensuring road safety in the Republic of Uzbekistan for 2018-2022, approved by the Resolution of the Cabinet of Ministers dated May 19, 2018 No. 377 "On measures to further improve the road safety system in the Republic of Uzbekistan", increasing the level of road safety is one of the priority areas for the country. The creation of an emergency response system in case of accidents in Uzbekistan will contribute to the achievement of the goals of the Concept and reduce the number of victims and serious consequences for the health of citizens as a result of road accidents.

\section{Characteristics}

The module installed in the car allows you to quickly 
contact emergency services in the event of an accident. The built-in chipset records the coordinates of the damaged vehicle. The position of the vehicle, the severity of the accident and the VIN are transmitted to the system. It filters false signals, and data on real accidents are transmitted to the emergency response system or to the duty department of the Ministry of Internal Affairs. According to the non-profit partnership "GLONASS", the emergency response system in case of accidents will save the lives of four thousand people annually. It reduces the response time of emergency services to an accident, and according to statistics, about $90 \%$ of those injured in an accident can be rescued if they receive assistance within 10 minutes. Communication is ensured by a SIM card built into the module, operating according to the full MVNO standard. It works wherever there is a coverage area of any mobile operator. For negotiations with the operator on duty, built-in speakers and a microphone are provided. Trucks or buses must be equipped with a manual release system. Passenger cars are devices that are automatically triggered in the event of an accident from an accelerometer or an airbag sensor. In any case, a manual call with the SOS button is also provided.

Russia put into operation the ERA-GLONASS system in 2015 and became the first state where such a service was deployed throughout the country. Over the years of operation, the system has shown itself to be a highly efficient service and has helped save the lives of over 1,500 motorists and preserve the health of thousands of victims of road accidents. The main tasks of ERA-GLONASS are to reduce mortality by automating information and speeding up the arrival of emergency services at the scene of an accident and preventing damage to the life and health of citizens. Today, more than 7 million vehicles are registered in the system, and their number is increasing daily by an average of 5,200 vehicles. The system has received more than 10 million calls, every 5 seconds ERA-GLONASS processes one emergency call. Over $70 \%$ of true calls come in automatic mode as a result of a severe accident, when the victim may not be able to call for help on his own.

\section{Practical research}

During the design and implementation of ERAGLONASS, specialists have developed innovative technologies and test methods, acquired unique knowledge and experience that they are ready to share with other countries. In all its developments, it adheres to the principle of technological neutrality, which avoids monopolization of technologies, provides a flexible transition to new solutions and broad export opportunities. JSC "GLONASS" will help Uzbek partners, who are also ready to apply their competencies in a joint project, to adapt the best Russian practices to the needs of Uzbekistan.

To diversify its business, GLONASS JSC, in addition to the transport sector, actively interacts with organizations of the agro-industrial complex, urban planning, the energy sector, natural resources, housing and communal services. The company develops innovative services within the entire navigation and information industry, including monitoring of transport and cargo (including for transit traffic and the organization of a "green corridor"), high-precision positioning technologies, insurance telematics, multifunctional platforms for intelligent transport systems (ITS) and others. Also, JSC "GLONASS" is the largest operator in the Internet of Things in Russia. The company is actively introducing all these products and services in many regions of the Russian Federation and is ready to offer them to government and commercial organizations of Uzbekistan.

\section{Conclusions}

The creation in the Republic of Uzbekistan of an emergency response system in case of road accidents will allow in the future to develop its navigation and information services in the country and expand its application to all types of transport. The General Director of GLONASS JSC Igor Milashevsky expressed confidence that the creation of an emergency response system in case of accidents in Uzbekistan would be a serious contribution to the digitalization of the country's transport industry. In his speech at the main plenary session of the interregional forum "Russia-Uzbekistan: Industrial Dialogue", Igor Milashevsky noted that the development of the system will contribute to improving the living standards of citizens and the development of the state's economy, will create a market for navigation and telematics equipment in Uzbekistan and create preconditions for the emergence of new workplaces.

To plan further steps on the project to create an emergency response system in Uzbekistan in case of accidents, the management of GLONASS JSC held negotiations with representatives of the Ministry of Internal Affairs, the Ministry of Transport and the Ministry for the Development of Information Technologies and Communications of the Republic of Uzbekistan. The Uzbek executive authorities expressed great interest in the project to create an emergency response system in case of road accidents and expressed support for its implementation.

At present, emergency response systems in case of accidents are also deployed in all countries of the European Union and in Kazakhstan, work on the creation of systems is underway in other states. In order to provide mutual assistance to car owners in case of accidents during crossborder trips, work is underway to organize information interaction between the Russian ERA-GLONASS system, Kazakhstan's EVAC and European eCall systems.

1. Satellites maintain communication with each other and with a ground station: they send radio signals to the ground information about the coordinates and time of signal transmission.

2. The GLONASS receiver, which is embedded in vehicles, determines the distance to several visible satellites. The result is calculated from the travel time of the signal from the satellite to the receiver.

3. The sensor monitors and records in the built-in memory the changing coordinates of the satellites, goes online via a SIM card and sends information to the server.

4. The server receives the received data and stores it in the database.

5. The system processes the information stored on the server, forms routes on the map, makes various reports on the operation of vehicles and drivers - travel time, driving speed, stops for refueling and others. 
There are 24 GLONASS satellites in orbit, they are equally distributed in each hemisphere. At any point on the earth above the horizon, at least four spacecraft are visible, not counting the backup ones.

Reserve satellites are needed to quickly replace a regular satellite if it fails. But even in the standby mode, they work and help to more accurately determine the coordinates of the GLONASS sensors. The more satellites, the more accurate the coordinates.

GLONASS OR GPS TRANSPORT MONITORING: WHAT IS THE DIFFERENCE

GPS (Global Positioning System) - the same satellite system, but of American production. The main difference between the GPS system and GLONASS satellites is that they are synchronized with the rotation of the Earth. The devices of the American system are located closer to the equator, while the Russian system is more polar. Due to this arrangement of orbits, satellite monitoring of GLONASS vehicles surpasses GPS in signal quality in the north.

Many companies use both systems at the same time, which greatly increases the accuracy of the coordinates. Ground equipment receives and compares information from two sources and corrects inaccuracies.

Depending on the needs of the business, the GLONASS vehicle monitoring system can be integrated with additional trackers: fuel control sensors, mechanism operation sensors, and others.

\section{Problems When Data Is Not Enough for Effective Vehicle Control.}

1. Idle runs. Satellite systems GLONASS and GPS do not constitute the route of the trip. The driver himself chooses how he will go from point A to point B. He may choose not the most optimal route or make it up according to his plans. The car is not used for work purposes, while the manager pays for the driver's working hours and fuel consumption.

2. Long search and waiting for the car. GLONASS and GPS do not show what mode the company car is in now: it is executing or waiting for an order, at lunch or during maintenance. Therefore, the employee has to call and check with the driver. The search for the car is delayed.

3. Low driver productivity. GLONASS and GPS monitoring systems do not track the number of orders completed by the driver. Therefore, he has no motivation to fill more orders. He gets the same salary for 3 trips a day and 10 .

4. Uneven use of vehicles. GLONASS and GPS do not monitor the uniform use of vehicles. Often the car is chosen based on the human factor: because of friendship, personal sympathy, or whoever is closer. For example, a garage manager may not consider how many trips the driver has made. He will send to order the closer one. It will probably be the driver who made the most trips.

However, GLONASS and GPS sensors can still be useful in vehicle fleet monitoring. Some of them show low or zero vehicle mileage - a clear sign that the fleet can be optimized.

For example, analyze whether your fleet really needs so many cars, and how to correctly use them in the work. But for this, you need to turn to other systems.

Software package. Customized for the specifics of your company. It takes into account the assigned and shared cars, the number of cars and employees.

Organization cabinet. Helps to keep records in the vehicle fleet, manage applications, change the number of drivers and cars.

Mobile application for employees. Allows you to order a trip in a few seconds and see where the car is at the moment.

Mobile application for drivers. Allows you to see orders in real-time, take an order to work without the participation of a dispatcher.

As a result of using TM: Corporate Travel, you will not only see your location, distance traveled and fuel level. You can analyze the efficiency of your fleet, increase driver productivity and reduce maintenance costs.

As a result of the implementation of the joint project, the Republic of Uzbekistan will become another country where the emergency response system in case of accidents will be an example of the effective use of advanced navigation and information technologies to ensure the priority functions of the state to prevent damage to the life and health of citizens following international law. In addition, the joint RussianUzbek project will open up new opportunities for business and the state and will increase the level of transport security of the country.

\section{References}

1. Donchenko, V.V. Management of road safety in motor transport enterprises of various forms of ownership: textbook. benefits / V.V. Donchenko, A.A. Stepanov, K.A. Ibraev. M.: NIIAT, 2008 .-- 128 p.

2. Kichedzhi, V.N. Moscow. Transport problems of a megalopolis / V.N. Kichedzhi, K. Hatoyama. - M.: KDP Press, 2010.11284 p.

3. Komarov, V.V. Intelligent tasks of telematic transport systems and intelligent transport system / V.V. Komarov, S. A. Garagan // T-Comm - Telecommunications and Transport. - 2012.- No. 4. - S. 34-38.

4. Merenkov, A. O. The concept and essence of intelligent transport systems. Features of the introduction of foreign experience in the Russian Federation / A.O. Merenkov // Management of the economy and development strategies of Russia - 2014: Materials of the international management forum. - Vol. 2 - M.: GUU, 2014. 187-189.

5. Intelligent Transportation System of the United States of America [Electronic resource]. - Access mode: http://www.itsa.org (date of access: 04/13/2015).

6. European Intelligent Transport System [Electronic resource]. - Access mode: http://www.ertico.com (accessed: 04/13/2015).

7. Intelligent transport system of Japan [Electronic resource]. - Access mode: http://www.itsjp.org (date of access: 04/13/2015).

8. Resolutions of the President of the Republic of Uzbekistan No. PP-2158 dated 04/03/2014 and No. PP-2569 dated 01/08/2016.

9. Decree of the President of the Republic of Uzbekistan "On a legal experiment to introduce a special management order in the city of Tashkent" No. UP-5515 of 08/17/2018. 